\title{
Impact of Technology on Smallholder Wheat Production in Bale Highlands of Ethiopia: Application of Output Decomposition Model
}

\author{
Mengistu Ketema $^{1 *}$, Belay Kassa ${ }^{2}$ \\ Article history: \\ Received 14 November 2015 \\ Accepted 16 May 2016 \\ Available online, ISSN: 2148-127X
}

${ }^{1}$ Department of Agricultural Economics, Haramaya University, P.O. Box 48, Haramaya, Ethiopia ${ }^{2}$ Pan African University, African Union Commission, P.O. Box 3243, Addis Ababa, Ethiopia
Keywords:

Wheat technology

Decomposition model

Production function

Impact, Ethiopia

Corresponding Author:

E-mail: mngistuket@gmail.com \begin{abstract}
A B S T R A C T
In Ethiopia, the national agricultural research system has been generating and disseminating different agricultural technologies since its establishment in 1966. Although these technologies are meant to increase agricultural productivity, they have to be evaluated for their impact on production and for the benefit that the farmers get out of them. Hence, the main objectives of this study were to examine the impact of technological innovations on wheat production and to decompose the total change in wheat output resulting from the introduction of new technologies into its constituent parts. Cobb-Douglas production function was employed to estimate the regression coefficients under old variety growers, new variety growers, and pooled data cases. Output decomposition model was applied to decompose the total change in output into its constituent parts. The econometric results of this study indicated that, out of $55 \%$ of the observed productivity difference between old and new variety grown plots, technological change and change in associated input levels contributed about $24 \%$ and $31 \%$, respectively. Of the $31 \%$ increment attributed to input use levels, an increased use of herbicides and fertilizers caused the biggest jump in the productivity of improved wheat varieties (15.5\% and $11 \%$ respectively). The major implications included the need to exploit the full potential of new varieties using recommended input levels, strengthening the research system, fostering coordinated efforts among various actors in agricultural development, and strengthening the technology instrument in rural development and poverty reduction strategies of the country.
\end{abstract}

\section{Introduction}

Agriculture is the most dominant and important sector in Ethiopia. Its economic importance stems primarily from its contribution to the Gross Domestic Product (GDP), merchandise exports, and employment. The sector accounts for about 39.9 percent of the GDP and 85 percent of employment for the population. The average share of crop production, livestock production, and forestry in the total agricultural value added was 70.7, 20.6, and 8.7 percent, respectively (NBE, 2014). Consequently, the overall performance of the country's economy is highly correlated with the performance of the agricultural sector.

The large majority of farmers in Ethiopia are smallholders where more than 83 percent of the farm households (12.1 million households) in 2014 have a land holding of 2 hectares or less (CSA, 2015a). Given this small land holding, it would be a challenge for the country to feed the ever increasing population unless improvement measures are implemented in the farming practices. There should be a means to speed up agricultural output growth and to relieve the pressure of population on food supplies. However, the increasing demand for food cannot be met by increasing production from area expansion since that has already become a minimal source of output growth. It needs to increase crop productivity.

For the fact that technological change is commonly considered as one of the major forces leading to successful productivity growth in agriculture, boosting agricultural productivity in Ethiopia calls for, among others, utilization of improved agricultural technologies. Agricultural growth must be considered as the key component of agricultural development strategy targeted for achieving sustainable food security at national and household levels. Improvement in agricultural productivity, therefore, requires introducing modern and appropriate agricultural technologies together with wellorganized extension services and development of infrastructure. Hence, transforming agriculture and expanding its productive capacity is a prerequisite for sustained economic development.

The role of agricultural research is central and decisive to this development process as it is the basis for raising the productivity of smallholder farmers. In this line, efforts are being made by the national agricultural research system to generate and disseminate technologies 
which are meant to increase productivity. Some progress has also been made in using improved agricultural technologies and inputs. For instance, the area covered by improved seed, which was about 0.6 per cent in 1991/92, grew up to 4.22 per cent in $2000 / 01$ and to 8.6 percent in 2014. During the same period, the area to which fertilizer was applied increased from about 32 percent to 38 percent and 67 percent of the cultivated area, respectively (CSA, 1992; CSA, 2001; CSA, 2015b).

Wheat is among the major cereal crops that received considerable focus by the national agricultural research system. This is justifiable because of the fact that wheat is among the most important crops not only in Ethiopia but also worldwide. It has played a significant role in feeding a hungry world and improving global food security. It contributes about $20 \%$ of the total dietary calories and proteins worldwide (Shiferaw et al., 2013).

Studies that considered development of improved wheat varieties and cultural practices in Ethiopia were initiated during the 1950s and 1960s by the then Institute of Agricultural Research (IAR) (now the Ethiopian Institute of Agricultural Research, EIAR) and Alemaya University (now Haramaya University) (Tesfaye et al, 2001). Since then, the national wheat research program has released and disseminated a number of bread and durum wheat varieties. A closer look at the proportion of the area covered by improved varieties of different crops showed that wheat took the second rank (7.4\%) next to maize (46.4\%) among cereals. Wheat is the most fertilized crop (82\%) among all crops. Pesticide application is also most common on wheat as compared to that on other cereal crops (CSA, 2015b).

The possible outcomes of a research undertaking are commonly conceptualized in terms of yield increases or avoided yield losses. However, such yield increases often require additional inputs, which lower the effective value of yield gains. Farmers, particularly resource-poor ones, will only adopt technologies if net yield gains are significantly greater than zero. It is then very important to know whether additional yields or returns obtained as a result of using improved technologies is sufficient enough to qualify the technology for wide-scale dissemination. Added to this, in developing countries like Ethiopia, some new agricultural technologies have been only partially successful in improving productive efficiency. One of the probable reasons might be farmers' deviation from the associated input levels of the developed technological packages. Farmers may not be able to apply optimum levels of inputs because of capital scarcity or lack of access to purchased inputs.

Even though a number of studies considered the adoption of new agricultural technologies in different parts of the country, nearly all of them were focused on identifying factors affecting adoption processes. Available evidence have shown that intensities and rates of adoption have been studied for different wheat technologies up to now. However, no study has been made to evaluate the contribution of improved technologies to the growth of agricultural productivity in Ethiopia.
However, the complex relationship between technology generation and other components of the agricultural economy necessitates systematic incorporation of quantitative information on the current technological environment. Moreover, the concept of research impact assessment is becoming increasingly important.

In view of understanding the contribution of improved wheat technologies to the growth of agricultural productivity in two districts (Sinana-Dinsho and Gassera) of the Bale highlands in Southeastern Ethiopia, the aim of the study is to examine the impact of technological innovations on wheat production and decomposing the total change in wheat output into its constituent parts.

\section{Materials and Methods}

\section{The Study Area}

The Southeastern part of Ethiopia is known for its extensive wheat production and it is sometimes called as "the wheat belt of Ethiopia" (Chintalapati et al., 2001). The study zone, Bale and the study districts, SinanaDinsho and Gassera, are located in this part of the country.

The major food crops grown in Bale are cereals, occupying 85.3 per cent of the cultivated area for temporary crops (43\% wheat, $11 \%$ barley, $16 \%$ teff, $9.2 \%$ maize, $3.8 \%$ Oats, and $2.4 \%$ sorghum) followed by oil crops covering 8.8 per cent, pulses occupying 5.9 per cent, and vegetables and root crops occupying less than one per cent of the cultivated area (CSA, 2015c). In 2014/15 production season, about 11 per cent of the country's wheat production and 18.7 per cent of wheat production in Oromiya is produced in Bale. The zonal yield average of wheat was 28.6 quintals per hectare in 2014/15 cropping season while the national average was 25.4 quintals per hectare (CSA, 2015).

Most of the districts in Bale highlands are known for their bimodal rainfall patterns and are, therefore, highly suitable for agriculture. The two seasons are meher and belg (Meher season in the area extends from August to December and is locally called as bona while the belg season extends from March to July and is locally called as ganna)

In Bale, especially in the highland districts, wheat can be grown in both seasons. The study districts, SinanaDinsho and Gassera, are among the wheat growing highland districts of the zone.

Though it is possible to grow pulses, oilseeds, vegetables and root crops, both Sinana-Dinsho and Gassera districts are highly suitable for cereal crops production. These districts are especially a high potential area for wheat production. In these district, wheat ranks first both in terms of area coverage and production.

Sinana Agricultural Research Center (SARC) is playing a leading role in generating and extending agricultural technologies in Bale. SARC is one of the research centers under Oromiya Agricultural Research Institute. The center has been conducting research on many highland food crops. The center has released many 
improved varieties of different crops and several farm management recommendations, for Bale highlands and for other areas with similar agro-ecologies. Among these, the majority are improved wheat varieties. The center also works intensively on dissemination of the released technologies to the wider farming community.

\section{Sampling Procedure}

A three-stage sampling technique was used to select sample respondents. In the first stage, out of seven wheat growing highland districts of Bale, two districts with relatively higher number of improved wheat technology users were selected purposively. In the second stage, based on the proportion of the number of peasant associations in the selected districts, a total of 12 peasant associations were randomly selected. In the final stage, a total of 122 farm households (60 from old variety growers and 62 from new variety growers) were selected randomly using probability proportional to size technique. These constituted a total of 114 new variety wheat plots and 84 old variety plots of the meher season and these plots are considered for econometric analyses.

\section{Analytical Framework}

Production function model: In order to investigate whether or not improved wheat technologies result in shift of the production function, output elasticities were estimated by Ordinary Least Squares (OLS) method by fitting Cobb-Douglas production function as:

$$
Y=A F^{a_{1}} L^{a_{2}} X^{a_{3}} H^{a_{4}} S^{a_{5}} T^{a_{6}} e^{u}
$$

Where:

$\mathrm{Y}$ is wheat output in $\mathrm{kg}$ per ha; F, L, X, H, S, and T are fertilizer in $\mathrm{kg}$ per ha, labor in man-days per hectare, oxen labor in oxen-pairs per hectare, herbicides applied in $50 \mathrm{ml}$ per ha, seed rate in $\mathrm{kg}$ per ha, and depreciation of farm tools (computed using straight line method) in Birr/ha; A is intercept term or scale parameter; $a_{j}$ is output elasticity of $\mathrm{j}^{\text {th }}$ input $(\mathrm{j}=1,2, \ldots, 6)$; $\mathrm{U}$ is random term which is independently distributed with zero mean and constant variance; and e is base of the natural logarithm $(\mathrm{e}=2.71828 \ldots)$.

Measuring the economic benefits of agricultural research requires comparison of the situation with research to its counterfactual in the absence of research (Marasas et al., 2003). Hence, equation 1 was estimated separately for old variety plots, new variety plots, and for the pooled data in its log-linear regression form as follows:

$$
\begin{aligned}
& \ln Y_{O i}=\ln A+a_{1} \ln F_{O i}+a_{2} \ln L_{O i}+a_{3} \ln X_{O i}+a_{4} \ln H_{O i}+a_{5} \ln S_{O i}+a_{6} \ln T_{O i}+U_{O i} \\
& \ln Y_{N i}=\ln B+b_{1} \ln F_{N i}+b_{2} \ln L_{N i}+b_{3} \ln X_{N i}+b_{4} \ln H_{N i}+b_{5} \ln S_{N i}+b_{6} \ln T_{N i}+U_{N i} \\
& \ln Y_{P i}=\ln C+c_{1} \ln F_{P i}+c_{2} \ln L_{P i}+c_{3} \ln X_{P i}+c_{4} \ln H_{P i}+c_{5} \ln S_{P i}+c_{6} \ln T_{P i}+U_{P i}
\end{aligned}
$$

\section{Where:}

$\mathrm{A}, \mathrm{B}$, and $\mathrm{C}$ are intercept terms or scale parameters for different functions; $a_{j}, b_{j}$, and $c_{j}(j=1,2, \ldots, 6)$ are output elasticities of $\mathrm{j}^{\text {th }}$ input under different functions; subscripts $\mathrm{O}, \mathrm{N}$, and $\mathrm{P}$ stand for production functions of old variety plots, new variety plots, and pooled plots, respectively; and $\mathrm{i}$ is plot observations (it is 1 to 84,1 to 114 , and 1 to 198 in equations 2,3 , and 4 respectively).

In order to check the severity of multicollinearity among explanatory variables, Variance Inflation Factor (VIF) is computed. VIF: Following Gujarati (1995), the $\mathrm{VIF}_{\mathrm{j}}$ is given as:

$$
V I F_{j}=\frac{1}{1-R_{j}^{2}}
$$

where $R_{j}^{2}$ is the coefficient of determination that results when the explanatory variable $\left(\mathrm{x}_{\mathrm{j}}\right)$ is regressed against all other explanatory variables. As $R_{j}^{2}$ increases toward unity, the VIF $_{\mathrm{j}}$ also increases and in the limit it can be infinity. If there is no collinearity between the explanatory variables, VIF will be 1 . VIF, therefore, ranges between one and infinity. As a rule of thumb, if VIF of a variable exceeds 10 , that variable is said to be highly collinear.
To check the homogeneity between parameters in production functions (2) and (3), a popularly used statistic called Chow's F-value was computed (Gujarati, 1995; Greene, 2000).

$$
F=\frac{\left\lfloor\sum e_{p i}^{2}-\left\{\sum e_{1 i}^{2}+\sum e_{2 i}^{2}\right\}\right\rfloor / k}{\left[\sum e_{1 i}^{2}+\sum e_{2 i}^{2}\right] /\left(n_{1}+n_{2}-2 k\right)}
$$

Where: $\sum \mathrm{e}_{\mathrm{pi}}{ }^{2}=$ unexplained variation due to production function of pooled data; $\sum \mathrm{e}_{1 \mathrm{i}}{ }^{2}=$ unexplained variation due to production function of old variety farms; $\sum \mathrm{e}_{2 \mathrm{i}}{ }^{2}=$ unexplained variation due to production function of new variety farms; $n_{1}$ and $n_{2}$ are sample sizes of old variety and new variety farms respectively; and $\mathrm{k}=$ number of parameters (including intercept).

If the F computed exceeds the critical $F$ value, reject the hypothesis that the parameters in the separate regressions are the same.

The significance of calculated Chow's F-statistic implies there is a structural change in production function because of the introduction of new varieties. If there is a change in the parameters of the two production functions, it can be said that the function has undergone a structural change (Gujarati, 1995). Structural change may mean that 
the two intercepts are different, or the two slopes are different, or both the intercept and the slopes are different. However, the above test does not tell whether the shift is in scale parameter (intercept term) or slope parameter (elasticity coefficients).
In order to identify whether the shift is in slope parameter or scale parameter, pooled production function was fitted by including intercept dummy as follows:

$$
\ln Y_{i}=\ln C+c_{1} \ln F_{i}+c_{2} \ln L_{i}+c_{3} \ln X_{i}+c_{4} \ln H_{i}+c_{5} \ln S_{i}+c_{6} \ln T_{i}+c_{7} D_{i}+U_{i}
$$

Where: $D_{i}$ is zero for old variety and one for new variety plots, and others are as defined earlier.

The significance of the coefficient for the slope dummy implies there is a shift in the intercept term. Again, in order to check whether there is a shift in the slope parameters, the Chow's F-value was re-computed by using residual sum of squares for the pooled production function with a dummy (Equation 5).
Output decomposition model: The output decomposition model developed by Bisaliah (1977), and used by different researchers (Kumar and Singh, 1980; Alishi et al, 1983; Kiresur et al., 1995; Gaddi and Kunnal, 1996; Shiyani, 1996; Badal and Singh, 2001), was used in this study.

Subtracting Equation 2 from Equation 3, adding and subtracting the same terms and making rearrangements the decomposition model can be specified as:

$$
\begin{gathered}
\ln \left(Y_{N} / Y_{O}\right)=[\ln (B / A)]+\left[\left(b_{1}-a_{1}\right) \ln F_{O}+\left(b_{2}-a_{2}\right) \ln L_{O}+\left(b_{3}-a_{3}\right) \ln X_{O}+\left(b_{4}-a_{4}\right) \ln H_{O}+\left(b_{5}-a_{5}\right) \ln S_{O}+\left(b_{6}-a_{6}\right) \ln T_{O}\right]+ \\
{\left[b_{1} \ln \left(F_{N} / F_{O}\right)+b_{2} \ln \left(L_{N} / L_{O}\right)+b_{3} \ln \left(X_{N} / X_{O}\right)+b_{4} \ln \left(H_{N} / H_{O}\right)+b_{5} \ln \left(S_{N} / S_{O}\right)+b_{6} \ln \left(T_{N} / T_{O}\right)\right]}
\end{gathered}
$$

Where: $Y_{N}, Y_{O}, F_{O}, L_{O}, X_{O}, H_{O}, S_{O}, T_{O}, F_{N}, L_{N}, X_{N}$, $\mathrm{H}_{\mathrm{N}}, \mathrm{S}_{\mathrm{N}}$, and $\mathrm{T}_{\mathrm{N}}$ are at the geometric mean levels.

The bracketed expression on the left side of the equation 6 is an approximate measure of total percentage change in output with the introduction of new wheat varieties. However, as the percentage change gets larger and larger, this expression will underestimate the observed difference in yields. In order to avoid this underestimation, both sides of equation 6 are multiplied by the correction factor ' $\delta$ ' as used by Gaddi and Kunnal (1996) and Shiyani (1996).

This equation is then rewritten as:

$$
\begin{gathered}
\left(\Delta Y / Y_{O}\right)=\delta[\ln (B / A)]+\delta\left[\left(b_{1}-a_{1}\right) \ln F_{O}+\left(b_{2}-a_{2}\right) \ln L_{O}+\left(b_{3}-a_{3}\right) \ln X_{O}+\left(b_{4}-a_{4}\right) \ln H_{O}+\left(b_{5}-a_{5}\right) \ln S_{O}+\left(b_{6}-a_{6}\right) \ln T_{O}\right]+ \\
\delta\left[b_{1} \ln \left(F_{N} / F_{O}\right)+b_{2} \ln \left(L_{N} / L_{O}\right)+b_{3} \ln \left(X_{N} / X_{O}\right)+b_{4} \ln \left(H_{N} / H_{O}\right)+b_{5} \ln \left(S_{N} / S_{O}\right)+b_{6} \ln \left(T_{N} / T_{O}\right)\right]
\end{gathered}
$$

Where

$$
\delta=\left[\Delta \mathrm{Y}_{\mathrm{O}}\right] \div\left[\ln \left(\mathrm{Y}_{\mathrm{N}} / \mathrm{Y}_{\mathrm{O}}\right)\right] \text {, and } \Delta \mathrm{Y}=\mathrm{Y}_{\mathrm{N}}-\mathrm{Y}_{\mathrm{O}}
$$

Now, the bracketed expression on the left side of the equation 7 is the observed difference in output with the introduction of new wheat varieties.

The first bracketed expression on the right hand side is a measure of percentage change in output due to shift in intercept term of the production function. It is a neutral component of technological change. The second bracketed expression is a measure of change in output due to shifts in slope parameters of the production function. This is a non-neutral component of technological change. Therefore, the sum of the first two bracketed components on the right hand side of equation 7 indicates the impact of improved wheat varieties.

The third bracketed term on the right hand side is the measure of change in output due to changes in volume of inputs per hectare, given the elasticities of inputs used under improved wheat production technology.

\section{Results and Discussions}

\section{Production Function Estimates}

The degree of multicollinearity among explanatory variables was tested using the technique of Variance Inflation Factors (VIF) before fitting econometric models. The values of VIF were very small and hence there was no serious problem of multicollinearity. Econometric models were fitted to the data of old variety plots (OVPs), new variety plots (NVPs) and for pooled plots using per hectare levels of both the dependent and the explanatory variables.

The estimates of the production functions under different scenarios were presented in Table 1. All the production functions were found to be significant at one per cent levels of probability. The adjusted coefficient of determination varied from 54.9 per cent to 63.5 per cent.

A closer look at Table 1 below revealed that the coefficients of fertilizer, herbicides, oxen power, and seed had positive signs and significant effect for all the production functions. However, the coefficient for labor was negative and significant for all models. The 
coefficient of farm implements was found to be positive and significant for the new variety plots and negative for the other cases. This coefficient was non-significant in the pooled function. Though no meaningful conclusions can be drawn from negative coefficients in Cobb-Douglas production function, the negative coefficients of labor and farm implements indicated the possibility of getting higher outputs with lesser units of these inputs (Raju, 1987). Hence, negative coefficient of labor implied that it was over utilized.

It may be recalled that in Cobb-Douglas production function, regression coefficients are synonymous with production elasticities. The model results also showed that the production elasticities of all the inputs were always applied less than optimal unites by diminishing marginal productivity of each input. Being the positive and less than one of the production elasticities of the inputs indicated that the input use levels stood at the rational zone of the production stages.

The production elasticities of fertilizer, herbicides, oxen power, and farm implements for the new variety plots production function were higher than that for the old variety plots production function. However, the opposite of this condition is true for the elasticity coefficients of labor and seed, and thus lower elasticity coefficients of labor and seed for the case of new variety might be due to the over utilization of these inputs in new wheat production technology.

\section{Sources of the Shift in Production Function}

It could be caused to increasing in the output levels by means of technological changes through shifting the values of scale and slope parameters of the production function. In order to test the overall significances of the differences of the production parameters between old and new wheat technologies, and then to measure the shift in production functions, the Chow's F-test was applied (Table 2).

$\mathrm{F}$ test score used to test the overall differences among production models was $8.53(\mathrm{p}<0.05)$ and it implied that there is a shift in production function due to the introduction of the new technology. However, in order to test whether the shift is of neutral (shift in scale parameter) or of non-neutral (shift in slope parameter) type, a pooled production function with intercept dummy was estimated (Table 3).

The coefficient for the dummy variable in the pooled production function was significant at one per cent probability level implying that the intercept for the new wheat technology was higher than that for the old variety production function. Thus, it could be stated that there was a neutral type of technological change resulting from the introduction of new wheat varieties. Computation of Chow's F-value using pooled function with a dummy resulted in a significant difference $(\mathrm{P}<0.05)$ in slope coefficients of the production functions under the old and the new wheat plots implying the presence of non-neutral technological change (Table 4).

On the whole, the calculated Chow's F-statistic was significant for the overall functions and for slope parameters implying thereby that the production functions for old and new varieties differed significantly. These differences were due to changes in the slope parameters and the intercepts.

As a concluding remark, the upward shift in the production function due to technological improvement was through a shift in the intercept (i.e. improvement in genetic quality of seed), and a shift in the slope (i.e. output elasticity with respect to various inputs).

Table 1 Estimates of production functions per hectare

\begin{tabular}{|c|c|c|c|c|c|c|}
\hline \multirow{2}{*}{ Explanatory variables } & \multicolumn{6}{|c|}{ Regression Coefficients } \\
\hline & \multicolumn{2}{|c|}{ For NVPs } & \multicolumn{2}{|c|}{ For OVPs } & \multicolumn{2}{|c|}{ Pooled } \\
\hline Fertilizer & $0.188 * *$ & $(0.083)$ & $0.102 * * *$ & $(0.025)$ & $0.131 * * *$ & $(0.023)$ \\
\hline Herbicides & $0.267 * * *$ & $(0.070)$ & $0.181 * * *$ & $(0.041)$ & $0.231 * * *$ & $(0.035)$ \\
\hline Labor & $-0.518 * * *$ & $(0.105)$ & $-0.350 * * *$ & $(0.090)$ & $-0.391 * * *$ & $(0.072)$ \\
\hline Oxen power & $0.199 * * *$ & $(0.074)$ & $0.155 * * *$ & $(0.049)$ & $0.162 * * *$ & $(0.042)$ \\
\hline Seed & $0.255^{* *}$ & $(0.120)$ & $0.659 * * *$ & $(0.146)$ & $0.649 * * *$ & $(0.100)$ \\
\hline Farm implements & $0.200 * * *$ & $(0.057)$ & $-0.219 * * *$ & $(0.064)$ & -0.029 & $(0.046)$ \\
\hline Intercept $^{\phi}$ & $5.700 * * *$ & $(0.767)$ & $4.734 * * *$ & $(0.805)$ & $4.257 * * *$ & $(0.568)$ \\
\hline Adjusted $\mathrm{R}^{2}$ & \multicolumn{2}{|c|}{0.55} & \multicolumn{2}{|c|}{0.64} & \multicolumn{2}{|c|}{0.57} \\
\hline F-Value & \multicolumn{2}{|c|}{$23.94 * * *$} & \multicolumn{2}{|c|}{$25.07 * * *$} & \multicolumn{2}{|c|}{$44.17 * * *$} \\
\hline Sample size (Number of plots) & \multicolumn{2}{|c|}{114} & \multicolumn{2}{|c|}{84} & \multicolumn{2}{|c|}{198} \\
\hline
\end{tabular}

Table 2 Chow test results to test the differences among old, new, and overall production models

\begin{tabular}{l|cccc}
\hline \multicolumn{1}{c|}{ Item } & $\mathrm{n}$ & $\mathrm{df}$ & Residual sum of squares & Chow's F-value \\
\hline Old variety & 84 & 77 & 11.16 & $8.53^{* *}$ \\
New Variety & 114 & 107 & 8.68 & \\
Pooled & 198 & 184 & 26.28 & \\
\hline
\end{tabular}

$\mathrm{n}$ : the number of observation; df: degrees of freedom; and $* * \mathrm{P}<0.05$ 
Table 3 Estimates of production function for pooled plots with intercept dummy

\begin{tabular}{|c|c|c|}
\hline Explanatory variables & Regression Coefficients & Standard Error \\
\hline Fertilizer & $0.121 * * *$ & 0.022 \\
\hline Herbicides & $0.199 * * *$ & 0.034 \\
\hline Labor & $-0.417 * * *$ & 0.069 \\
\hline Oxen power & $0.165 * * *$ & 0.040 \\
\hline Seed & $0.597 * * *$ & 0.095 \\
\hline Farm implements & -0.042 & 0.043 \\
\hline Intercept $^{\phi}$ & $4.628 * * *$ & 0.544 \\
\hline Intercept dummy (Farmers category) & $0.253 * * *$ & 0.054 \\
\hline Adjusted $\mathrm{R}^{2}$ & 0.61 & \\
\hline F-Value & $45.25 * * *$ & \\
\hline Sample size ${ }^{\S}$ & 198 & \\
\hline
\end{tabular}

${ }^{* * * *} \mathrm{P}<0.01,{ }^{\phi}:$ intercept is in natural logarithmic forms

Table 4 Chow test for Checking the Difference in the Slope Parameters

\begin{tabular}{l|cccc}
\hline \multicolumn{1}{c|}{ Item } & $\mathrm{n}$ & $\mathrm{df}$ & Residual sum of squares & Chow's F-value \\
\hline Old variety & 84 & 77 & 11.16 & $5.77 * *$ \\
New Variety & 114 & 107 & 8.68 & \\
Pooled with dummy & 198 & 183 & 23.53 & \\
\hline
\end{tabular}

$\mathrm{n}$ : the number of observation; df: degrees of freedom; and ${ }^{* *} \mathrm{P}<0.05$

Table 5 Parameter estimates for the function with both intercept and slope dummies

\begin{tabular}{|c|c|c|}
\hline Variables & Coefficients & Standard error \\
\hline Intercept $^{\phi}$ & $4.74 * * *$ & 0.693 \\
\hline Fertilizer & $0.102 * * *$ & 0.021 \\
\hline Herbicides & $0.181 * * *$ & 0.036 \\
\hline labor & $-0.349 * * *$ & 0.077 \\
\hline Oxen power & $0.154 * * *$ & 0.042 \\
\hline Seed & $0.659 * * *$ & 0.126 \\
\hline Farm tools & $-0.220 * * *$ & 0.055 \\
\hline Intercept dummy & 1.225 & 1.068 \\
\hline Slope dummies for & & \\
\hline a. fertilizer & 0.0814 & 0.098 \\
\hline b. herbicides & 0.087 & 0.088 \\
\hline c. human labor & -0.139 & 0.121 \\
\hline d. oxen labor & 0.041 & 0.087 \\
\hline e. seed & $-0.403 * *$ & 0.187 \\
\hline f. farm tools & $0.336 * * *$ & 0.068 \\
\hline Adjusted $\mathrm{R}^{2}$ & 0.66 & \\
\hline F-value & $30.77 * * *$ & \\
\hline
\end{tabular}

$\mathrm{p}<0.001{ }^{* *} \mathrm{p}<0.05 ;{ }^{\phi}:$ natural logarithmic form

The covariance analysis indicated that wheat varietal technology resulted in the change of the efficiency level of all inputs taken together, as the difference in the slope parameters was significant. However, it could not be concluded from these tests whether the slope coefficients of all the explanatory variables were different as between old and new technology or some of them were equal. This requires the use of dummy variable technique in order to identify which individual slope parameters were significantly different between the two technologies and which parameters are not. Hence, a pooled production function was estimated with both the intercept and slope dummies as follows.

$$
\begin{aligned}
\ln Y_{P i}= & \ln C+c_{1} \ln F_{P i}+c_{2} \ln L_{P i}+c_{3} \ln X_{P i}+c_{4} \ln H_{P i}+c_{5} \ln S_{P i}+c_{6} \ln T_{P i}+ \\
& c_{7} D_{i}+c_{8}\left(D_{i} \ln F_{P i}\right)+c_{9}\left(D_{i} \ln L_{P i}\right)+c_{10}\left(D_{i} \ln X_{P i}\right)+c_{11}\left(D_{i} \ln H_{P i}\right)+ \\
& c_{12}\left(D_{i} \ln S_{P i}\right)+c_{13}\left(D_{i} \ln T_{P i}\right)+U_{P i}
\end{aligned}
$$

Where; $D_{i}$ is dummy with a value referring zero for old variety and one for new one wheat plots.

The model results showed that the slope dummies, with the exception of the dummy variables for seed and farm implements, were not statistically significant (Table 5 ). Thus, the hypothesis of homogeneity in the regression coefficients of seed and tool between the two production functions was rejected whereas the same hypothesis was 
accepted in the case of all other inputs. Hence, it can be concluded that the technology significantly shifted the slope parameters of seed and farm tools, though the shift is negative in the case of seed. As the coefficient of seed input is negative and significant, the productivity of seed turned out to be relatively higher on the old variety plots, probably due to the relatively lower use of this input on the old variety plots as implied by the diminishing marginal productivity assumption of the Cobb-Douglas production functions. This was supported by the results of earlier studies, where the production elasticity of this input (seed) in the new variety plots was lower than that in old variety plots.

\section{Decomposition of Productivity Difference}

After having concluded that there was a structural break in wheat production relations, the total change in the output per hectare was decomposed using production function parameters and geometric mean levels with the help of decomposition equation (Equation 7). In this model, inputs and output were taken as their geometric mean levels (Table 6).

Table 6 indicated that all of the inputs used in new wheat variety cultivation were higher than those used on old variety plots. The output per hectare was also higher for new variety plots. If the benefits of the new technology are largely expressed as increased yield, the first step was to estimate yield changes due to adoption of that technology and then identify the constituent sources of that change.

A detailed examination of the productivity differences revealed that the contribution of neutral technological change to total productivity difference was of very high order (121.43 per cent); whereas the non-neutral technological change made a negative contribution to the total productivity gap (Table 7). The reduction in net efficiency level of various inputs taken together narrowed down the productivity gap by $97.4 \%$, while shifting from old variety to new variety technology. The main factors responsible for the negative non-neutral technological component were seed and human labor inputs.

On the other hand, it was observed that there was an increase in efficiency of fertilizer, herbicides, oxen power, and farm implements (40.8, 23.4, 19.4 and 157.8\%, respectively) through shift from old technology to new one. The implication of negative contribution of nonneutral technological component is that the resource use efficiency on the new variety plots should be increased by way of adopting the recommended package, especially seeding rate, on the cultivation practices in order to exploit the potential of the new variety.

An increased use of inputs per hectare under new production technology contributed about $31 \%$ to the increased output. An increased use of herbicides and fertilizers resulted in the biggest jump in the productivity of improved wheat varieties to 15.5 and $11 \%$, respectively. The other inputs which contributed positively to total productivity were seed, farm implements, and oxen power in that order. However, the use of labor contributed negatively to the total productivity. This is due to the over utilization of labor on new variety plots, as evidenced from the negative coefficient.

The contribution in productivity gap attributed to differences in the levels of input use indicated that the productivity on old variety plots could be increased by about $31 \%$ if the input levels per hectare on these plots could be increased to the same level as on new variety plots. However, if it was not possible for old variety growers to adopt completely the input use level of new variety plots, they could adopt the new wheat cultivars with the existing level of input use, which could earn them better returns (24\%). This implied that it is possible to raise output by about $24 \%$ if the farmers could just switch over from old to new wheat variety without changing their previous input levels. However, if the farmers could simultaneously raise the input use levels, the productivity could be further raised by another 31 per cent to make a total estimated productivity difference of about 55 per cent.

The results of the decomposition analysis showed that there was a slight discrepancy between the observed $(55.6 \%)$ and estimated $(54.7 \%)$ differences in productivity for the old and new wheat technologies. This discrepancy was attributed to the random error term, which among others, accounts for the variable management input that could not be included in the model. Such discrepancies of varying degree were also encountered in several earlier studies (Badal and Singh, 2001; Gaddi and Kunnal, 1996; Shiyani, 1996; Kiresur et al., 1995; Kumar and Singh, 1980; Bisaliah, 1977). However, in the present study, since the discrepancy in question was of very low order, the results of the decomposition analysis were considered satisfactory.

Table 6 Geometric mean levels of the inputs and output

\begin{tabular}{|c|c|c|}
\hline Output and Inputs & For NVPs & For OVPs \\
\hline Output (kg) & 2585.83 & 1661.04 \\
\hline Fertilizer (kg) & 69.31 & 43.62 \\
\hline Herbicides (50ml units) & 13.8 & 8.8 \\
\hline Labor (days) & 47.05 & 45.24 \\
\hline Oxen power (Oxen-pair) & 34.67 & 33.51 \\
\hline Seed $(\mathrm{kg})$ & 178.18 & 161.63 \\
\hline Tool (Birr) & 22.37 & 20.00 \\
\hline
\end{tabular}


Table 7 Sources of productivity difference between NVGs and OVGs

\begin{tabular}{|c|c|c|c|}
\hline \multirow{2}{*}{ S.no. } & \multirow{2}{*}{ Sources of Productivity Difference } & \multicolumn{2}{|c|}{ Percentage Contribution } \\
\hline & & Sub-total & Total \\
\hline A. & Total observed difference in productivity ${ }^{a}$ & & 55.6 \\
\hline B. & Due to difference in technology & & 24.07 \\
\hline & 1. Neutral Technological Difference ${ }^{b}$ & 121.43 & \\
\hline & Non-neutral Technological Difference ${ }^{c}$ & -97.36 & \\
\hline & a. Fertilizer & 40.81 & \\
\hline & Herbicides & 23.38 & \\
\hline & Labor & -80.50 & \\
\hline & Oxen power & 19.42 & \\
\hline & Seed & -258.25 & \\
\hline & f. $\quad$ Farm implements & 157.78 & \\
\hline C. & Due to difference in input use level ${ }^{\mathrm{d}}$ & & 30.65 \\
\hline & 1. Fertilizer & 10.95 & \\
\hline & Herbicides & 15.46 & \\
\hline & Labor & -2.55 & \\
\hline & Oxen power & 0.84 & \\
\hline & Seed & 3.13 & \\
\hline & 6. Tool & 2.82 & \\
\hline D. & Total estimated difference in productivity (all the sources) & & 54.72 \\
\hline
\end{tabular}

\section{Conclusions}

From the overall analyses, the following major conclusions and policy implications are drawn:

- Exploiting the full potential of the new varieties using recommended input levels: The negatively shifted elasticities of labor and seed inputs emanating from over-utilization of these inputs indicated the possibility of increasing productivity by adopting recommended levels. This implies that higher yields are still going to be attainable by promoting a combination of plant breeding, and improving crop management practices.

- Strengthening the research system: The contribution of technology generation efforts in providing agricultural growth in the country is enormous. Hence, it is imperative to strengthen the research system. Budgetary expenditure on technology development is inadequate as compared to the diversity of agricultural production that has to be addressed. Continued investments for the researches are, therefore, required to allow continued gains on the productivity. Encouraging a highly competitive and competent private sector involvement for the research lacking currently in Ethiopia is also necessary besides the public sector.

- Encouraging coordinated efforts among various actors in agricultural development: It would be irrational to assume that the problem of agricultural transformation can be addressed by the system of technology generation alone. As there are no technical solutions to some of the problems, the contribution of agricultural research is to present concrete research based findings to which other actors respond. The focus attention should be given to concerted efforts and better linkages among research, extension, seed companies, input and grain traders, farmers and farmers' organizations and policy makers.

- Strengthening the technology instrument in rural development and poverty reduction strategy of the country: Technology offers a huge potential to reduce the poverty for the smallholder agriculture. However, to effectively reduce the poverty, the technology instruments should be applied in a comprehensive rural development and poverty reduction strategy of the country.

\section{Acknowledgments}

We thank the Ethiopian Institute of Agricultural Research for financing this study through its Agricultural Research and Training Project.

\section{References}

Alishi MR, Kumar P, Mathur VC. 1983. Technological Change and Factor Shares in Cotton Production: A case study of Akola Cotton Farms. Indian Journal of Agricultural Economics, 38 (3): $407-415$.

Badal PS, Singh RP. 2001. Technological Change in Maize Production: A Case Study of Bihar. Indian Journal of Agricultural Economics, 56 (2): 211 - 219.

Bisaliah S. 1977. Decomposition Analysis of Output Change under New Production Technology in Wheat Farming: Some Implications of Returns on Research Investment. Indian Journal of Agricultural Economics, 32 (3): 193 - 201.

Chintalapati P, Kefyalew D., Kassahun T., Gubo Q., Andrey R. 2001. The Shift to Cereal Monocropping, a Threat or a Blessing? Towards Sustainable Agricultural Production in the Highlands of Southeast Oromiya, Ethiopia. ICRA-2001 Ethiopian team, Working Document Series 92, Ethiopia.

CSA (Central Statistical Authority). 1992. Agricultural Sample Survey. Report on Farm Management Practices, Private Peasant Holdings (Meher Season, 1991/92). 
CSA (Central Statistical Authority). 2001. Agricultural Sample Survey. Report on Farm Management Practices, Private Peasant Holdings (Meher Season, 2000/01). Statistical Bulletin no. 245.

CSA (Central Statistical Authority). 2015a. Agricultural Sample Survey 2014/15. Volume IV. Report on Land Utilization for Private Peasant Holdings, Meher Season. Statistical Bulletin 578, Central Statistical Agency, Addis Ababa, Ethiopia

CSA (Central Statistical Authority). 2015b. Agricultural Sample Survey 2014/15. Volume III. Report on Farm Management Practices for Private Peasant Holdings, Meher Season. Statistical Bulletin 578, Central Statistical Agency, Addis Ababa, Ethiopia

CSA (Central Statistical Authority). 2015c. Agricultural Sample Survey 2014/15. Volume I. Report on Area and Production of Major Crops for Private Peasant Holdings, Meher Season. Statistical Bulletin 578, Central Statistical Agency, Addis Ababa, Ethiopia

Gaddi GM. Kunnal LB. 1996. Sources of Output Growth in Milk Production Technology and Some Implications to Returns on Research Investment. Indian Journal of Agricultural Economics, 51 (3): 389 - 395.

Greene WH. 2000. Econometric Analysis. $4^{\text {th }}$ ed., Prentice-Hall International Inc., New Jersey, USA.

Gujaratti D. 1995. Basic Econometrics. $3^{\text {rd }}$ edition, McGraw-Hill, Inc. New York
Kiresur V, Pandey RK, Mruthyunjaya. 1995. Technological Change in Sorghum Production: An Econometric Study of Dharwad Farms in Karnataka. Indian Journal of Agricultural Economics, 50 (2): 185 - 192.

Kumar P, Singh RP. 1980. Dynamic Feed-Milk Relationship and Technological Change in Milk Production. Indian Journal of Agricultural Economics, 35 (4): 126 - 132.

Marasas CN, Smale M, Singh RP. 2003. The Economic Impact of Productivity Maintenance Research: Breeding for Leaf-rust Resistance in Modern Wheat. Agricultural Economics, 29: 253 263.

NBE (National Bank of Ethiopia). 2014. Annual Report for the Year 2013/2014. Economic Research Department of National Bank of Ethiopia, Addis Ababa.

Raju SKV. 1987. Analysis of Productivity Levels and Economic Efficiency in Agriculture. Chugh Publications, Allahabad, India. Shiyani RL. 1996. An Economic Inquiry into the Impact of Dairy Co-operatives on Milk Production. Indian Journal of Agricultural Economics, 51 (3): 396 - 406.

Singh SR. 1986. Technological Parameters in Agricultural Production Function. Ashish Publishing House, 8/81, Punjabi bagh, New Delhi.

Shiferaw B, Smale M, Braun HJ, Duveiller E, Reynolds M, Muricho G. 2013. Crops that feed the world 10. Past successes and future challenges to the role played by wheat in global food security. Food Security, 5: 291-317. DOI 10.1007/s12571-013-0263-y

Tesfaye Zegeye. 2001. The Impact of Technology Development and Transfer: The case of Maize in Ethiopia. Research Report No. 42, EARO, Addis Ababa, Ethiopia. 